\title{
VIII. ON THE NUMBER OF PLAGUE BACILLI IN THE BLOOD, URINE, AND FAECES RESPECTIVELY OF RATS WHICH HAD DIED OF PLAGUE.
}

We have approached this subject by, in the first place, making a quantitative estimation of the number of plague bacilli present in the blood and urine of rats either recently dead of plague or in a moribund condition from that disease, and, in the second place, by determining the percentage of Bombay rats, which it was possible to infect by rubbing on the scarified skin the faeces of rats which had died of plague and in the blood of which the bacillus was present in enormous numbers.

A. Blood and urine. The method adopted throughout was briefly as follows:-

In most instances the rat, being ill and apparently moribund, was killed with chloroform; in some cases, however, the animal was allowed to die and the examination made immediately after death. The blood was always drawn directly from the heart, after the wall had been sterilised with the actual cautery. It was at once mixed with an equal volume of a 2 per cent. solution of citrate of soda dissolved in normal salt solution. The urine was pipetted directly from the bladder after the wall had been sterilised with the actual cautery.

The dilutions were effected by means of one of Wright's diluting pipettes, the stem of which was graduated in divisions of five cubic millimetres capacity up to 50 cubic millimetres, the remaining graduation mark indicating 500 cubic millimetres. The pipette was sterilised in the flame before use. The dilution fluid employed was in all cases sterile broth.

T'wo series, each of three sterile and covered watch glasses, were placed in front of the operator, one series for the blood and the other for the urine. Into the first of the blood series 490 cubic millimetres of broth were measured and into all the other glasses 495 cubic millimetres. Now, taking first the blood, 10 cubic millimetres of the 
citrated blood were measured into the first watch glass, giving in this glass a dilution of 1 in 100 . Before sterilising the pipette, 200 cubic millimetres and 20 cubic millimetres of the undiluted citrated blood were inseminated into two separate flasks of oil broth, numbered 1 and 2. The pipette was then sterilised by washing it out two or three times with boiling sterile water. After the pipette had been cooled by rinsing out with sterile broth the dilution of 1 in 100 was thoroughly mixed and five cubic millimetres transferred to the second watch glass, thus giving in this latter glass a dilution of 1 in 10,000. From the 1 in 100 dilution, 100 cubic millimetres and 10 cubic millimetres were planted ont separately into two broth tubes, numbered 3 and 4 . In the same manner the dilution of 1 in 1,000,000 was prepared and cultures made from the 1 in 10,000 dilution and from this higher dilution. The following table shows the amount of the original blood in each culture tube, and how this was arrived at:

\begin{tabular}{|c|c|c|c|c|c|}
\hline \multirow{2}{*}{$\begin{array}{l}\text { No. of } \\
\text { culture tube }\end{array}$} & $\begin{array}{l}\text { Dilution of blood } \\
\text { from which } \\
\text { prepared }\end{array}$ & \multicolumn{2}{|c|}{$\begin{array}{c}\text { Amount of dilution } \\
\text { inseminated into } \\
\text { culture tubes }\end{array}$} & \multicolumn{2}{|c|}{$\begin{array}{l}\text { Amount of undiluted } \\
\text { blood in each tube }\end{array}$} \\
\hline & 2 fold (citrated) & $200 \mathrm{c}$ & $\mathrm{mm}$. & 0.1 & c.c. \\
\hline ," 2 & & 20 &, & 0.01 & , \\
\hline Tube 3 & 100 fold & 100 & , & 0.001 & , \\
\hline 4 & , & 10 & , & 0.0001 & , \\
\hline , & 10,000 fold & 100 & ," & 0.00001 & , \\
\hline , & " & 10 & ", & 0.000001 & $n$ \\
\hline$"$ & $1,000,000$ fold & 100 &, & 0.0000001 & $n$ \\
\hline 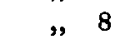 & , & 10 & , & 0.00000001 & " \\
\hline
\end{tabular}

In some few instances a dilution of 1 in 100,000,000 was prepared and of this dilution 100 cubic millimetres and 10 cubic millimetres were planted out.

The urine was treated in a similar manner. But, as it was in the first instance undiluted, 100 cubic millimetres and 10 cubic millimetres were planted into flasks 1 and 2 respectively, and for the preparation of the dilution of 1 in 100 , five cubic millimetres of urine were added to 495 cubic millimetres of broth. In a few instances the bladder was empty and no enumeration could be made, while in other cases the amount of urine obtained was not sufficient to inseminate the first flask with 100 cubic millimetres. Notice is taken of these exceptions in the table of results.

After the flasks and tubes had been inseminated in the manner described above, they were kept at laboratory temperature (about $24^{\circ} \mathrm{C}$.) for ten days. The flasks of oil broth then as a rule showed the typical 
growth of $B$. pestis, while the growths in the tubes were also characteristic of this organism. If, however, there was any doubt of the purity of the growth, it was carefully tested by other cultural methods.

Working in this way we have enumerated the bacilli in the blood of 32 rats, the urine of 21 of these being examined at the same time. The result of these enumerations is summarised in the table below, on the figures contained in which a few comments may now be made.

\begin{tabular}{|c|c|c|c|c|}
\hline Animals 1 & $\begin{array}{c}\text { Killed or } \\
\text { died }\end{array}$ & $\begin{array}{c}\text { Day after } \\
\text { inoculation on } \\
\text { which killed } \\
\text { or died }\end{array}$ & $\begin{array}{c}\text { Number of organisms in } \\
1 \text { c.c. of blood }\end{array}$ & $\begin{array}{l}\text { Number of organisms } \\
\text { in } 1 \text { c.c. of urine }\end{array}$ \\
\hline Rat A 1 & killed & 2 & $10-100$ & - \\
\hline , B2 & , & $\mathbf{3}$ & $100-1000$ & - \\
\hline "B4 & died & 4 & $10,000-100,000$ & $100-1000$ \\
\hline,$\quad \mathrm{C} 5$ & killed & 2 & $10,000-100,000$ & $\longrightarrow$ \\
\hline , C 10 & ", & 3 & $\operatorname{not} 10^{2}$ & - \\
\hline " C 7 & , & $\mathbf{3}$ & $10-100$ & - \\
\hline$"$ D 5 & died & 4 & $100-1000$ & $\longrightarrow$ \\
\hline , D 15 & killed & 3 & $10,000-100,000$ & not 12 \\
\hline , D 16 & $"$ & 3 & $100,000-1,000,000$ & not 10 \\
\hline , D 6 & died & 5 & not 10 & not 10 \\
\hline,$\quad$ F 6 & killed & 4 & $10-100$ & not 10 \\
\hline,$\quad \mathbf{F} 9$ & ", & 4 & $10,000,000-100,000,000$ & $50-1000$ \\
\hline,$\quad$ F 12 & died & 4 & $10,000,000-100,000,000$ & $10,000-100,000$ \\
\hline,$\quad \mathbf{G 2 1}$ & $"$ & 4 & $1000-10,000$ & not 10 \\
\hline „ Н 19 & $"$ & 3 & $1,000,000-10,000,000$ & not 50 \\
\hline " &, & 2 & $10,000-100,000$ & $\longrightarrow$ \\
\hline , J 33 & $"$ & 2 & At least $100,000,000$ & not 10 \\
\hline , J 35 & $"$ & 3 & At least $100,000,000$ & - \\
\hline,$\quad \mathbf{J} 4$ & killed & 7 & $\operatorname{not} 10$ & not 20 \\
\hline , $\mathbf{M} \mathbf{3}$ & ", & 6 & $10,000-100,000$ & not 10 \\
\hline " M 14 & , & 5 & $100,000-1,000,000$ & not 10 \\
\hline$" \quad 010$ & ", & 2 & $100-1000$ & $\operatorname{not} 10$ \\
\hline , U 3 & died & 4 & $100,000-1,000,000$ & not 10 \\
\hline No. 1478 & killed & 3 & $100,000-1,000,000$ & not 10 \\
\hline , 1545 & $"$ & 4 & At least $100,000,000$ & $1000-10,000$ \\
\hline ,, 1588 & $"$ & 2 & $10,000,000-100,000,000$ & $\longrightarrow$ \\
\hline , 1736 & died & 3 & $10,000,000-100,000,000$ & not 10 \\
\hline , 1835 & ", & 2 & $10,000-100,000$ & $\longrightarrow$ \\
\hline , 1855 & killed & 2 & $100,000,000-1,000,000,000$ & $16-1000$ \\
\hline ,, 1851 & " & 2 & $100,000,000-1,000,000,000$ & $66-1000$ \\
\hline ,, 1854 & ," & 3 & At least $100,000,000$ & - \\
\hline, 2056 & " & 2 & $10,000-100,000$ & not 100 \\
\hline
\end{tabular}

1 The first 23 rats were inoculated cutaneously with the fresh spleen of rats dead of acute plague; the last nine rats were inoculated subcutaneously with cultures of virulent plague.

${ }^{2}$ i.e. no growth was obtained in the largest quantity examined, i.e. in $0 \cdot 1$ c.c. 
First, it will be seen that in three instances no growth was obtained from the blood. In all of these cases plague bacilli were found in smears made from the bubo and spleen. In two of these cases, however, the animals had been killed, so we are not justified in assuming that bacilli would not have appeared in the blood before death. In the case in which the rat had been allowed to die, no growth was obtained from the urine.

Secondly, it will be seen that the blood may contain an enormous number of plague organisms even before the death of the animal. In the cases in which the rats were killed it is of course possible that a great increase would have taken place before death. It is also to be remembered that in the case of the rats which were allowed to die the experiment was begun immediately after death. The figures, therefore, show that any suctorial insect feeding on an infected animal would have ample opportunity of taking many plague bacilli into its stomach in the course of an epizootic among rats.

Thirdly, we have to compare the number of organisms present in the blood with the number present in the urine. A reference to the table will show that we have estimated the number of organisms present simultaneously in the blood and urine in the case of 21 rats. In two of these observations no bacilli were grown either from the blood or from the urine. In the other nineteen cases the blood contained bacilli in 13 instances in which no growths were got from the urine. Further, it will be seen that the blood may contain as many as from $10,000,000$ to $100,000,000$ bacilli per c.c., and still the urine may not have even 10 per c.c. $(J 33,1736)$. When now we come to examine the enumeration figures in the six instances in which growths of $B$. pestis were got from the urine, it is seen that the blood always contained very many times more bacilli than the urine, the number in the latter fluid being from 100 to $1,000,000$ times less than in the blood.

$B$. Faeces. In these experiments the faeces of rats dead of septicaemic plague were rubbed into a shaved and scarified surface on the abdomen of fresh rats. Klein ${ }^{1}$ (1904) says that the tubules of the kidneys of rats inoculated with plague contain bacilli and therefore presumably the urine will also contain them; also that the intestine in acute and subacute forms of plague always contains sanguineous mucus, which when inoculated cutaneously upon rats produces fatal plague. He does not mention the number of observations which he made upon this point, but concludes that the faeces and urine of rats

1 Klein (1904), Rep. of the Med. Officer Local Government Board. Appendix B, No. 1. 
are important means of spread of the disease amongst rats, and also probably amongst human beings. Our method was as follows :-

The rats from which the faeces were obtained had been allowed to die. After the abdomen had been opened, the anterior wall of the rectum was lightly seared with a hot iron. By means of sterile scissors the burned portion was opened up and any faeces carefully removed with a pair of suitable forceps. In this way it was hoped to avoid, as far as possible, any contamination of the faeces with the blood or peritoneal fluid of the animal. It was of course impossible to make certain that this desideratum had been accomplished. Only those rats, in the blood of which abundant plague bacilli were present, were used. The faeces obtained in the manner described were made into a thick emulsion with sterile broth. The emulsion was then rubbed into a scarified surface on the fresh rats' abdomen.

Working in this way we have inoculated 139 rats ; of these 36 died from some disease other than plague, thus leaving 103 which were observed throughout. Of these 103 rats only three died of plague, giving a mortality rate of about 2.9 per cent. on the total number under observation. From these observations it would appear that in nature the chances of rats becoming infected from faeces being rubbed in cutaneously are remote and probably of little account from an epidemiological point of view.

\section{Summary and Conclusions.}

The blood of plague-infected rats may contain an enormous number of plague bacilli, even as many as $100,000,000$ per c.c. having been found before death. On the other hand rats occasionally die from plague with little or no septicaemia. An insect sucking the blood of most rats shortly before death would imbibe a large number of bacilli.

While the blood of a rat may have as many as $100,000,000$ organisms in a c.c. the urine may have none at all, or at least less than 10 per c.c. Plague bacilli were discovered in the urine in 29 per cent. of the cases. When the urine does contain plague bacilli they are always present in much fewer numbers than in the blood.

The faeces of rats dead of plague and the blood of which contained abundant bacteria are not highly infective and would appear to play little part in the spreading of the epizootic. 